\title{
Editorial \\ Theoretical Chemistry of Atmospheric Processes
}

\author{
Luís Pedro Viegas
}

check for

updates

Citation: Viegas, L.P. Theoretical

Chemistry of Atmospheric Processes. Atmosphere 2022, 13, 309. https:// doi.org/10.3390/atmos13020309

Received: 7 February 2022

Accepted: 10 February 2022

Published: 12 February 2022

Publisher's Note: MDPI stays neutral with regard to jurisdictional claims in published maps and institutional affiliations.

Copyright: (C) 2022 by the author. Licensee MDPI, Basel, Switzerland. This article is an open access article distributed under the terms and conditions of the Creative Commons Attribution (CC BY) license (https:// creativecommons.org/licenses/by/ $4.0 /)$.
Coimbra Chemistry Center-Institute of Molecular Sciences, University of Coimbra, 3004-531 Coimbra, Portugal; lpviegas@ci.uc.pt

Atmospheric chemistry occurs within a fabric of profoundly complicated dynamics through several atmospheric layers. Understanding the underlying theoretical details of the atmosphere's chemical processes is of fundamental importance, not only to assist the interpretation of observational/field and laboratory measurements, but also to contribute to the building blocks of theoretical models with good predictive capabilities. Priority societal challenges such as climate change mitigation of course benefit from the knowledge resulting from atmospheric chemistry research which guides the necessary policies to mitigate the hazardous consequences of climate change.

In this Special Issue on "Theoretical Chemistry of Atmospheric Processes", five original research articles report recent findings describing the modelling of reactions and processes taking place in the atmosphere, while a review finishes this Special Issue. The research articles span a variety of subjects: $\mathrm{N}_{2}+\mathrm{H}_{2}$ reactive collisions [1], sulfuric acid-base cluster formation [2], the reaction mechanism of ethylbenzene- $\mathrm{OH}$ adduct with $\mathrm{O}_{2}$ and $\mathrm{NO}_{2}$ [3], kinetics of reactions of ozone with halogen atoms ( $\mathrm{Cl}, \mathrm{Br}$ and $\mathrm{I})$ [4] and an empirical model for ozone concentration highlighting the roles of isoprene and monoterpenes [5]. Finally, a review paper presents us a proposal for a programme of research for theoretical chemistry where atmospheric turbulence is properly discussed [6].

This editorial provides highlights of such articles. In the first piece, Garrido and Ballester [1] perform a theoretical study of the $\mathrm{N}_{2}\left(v^{\prime}\right)+\mathrm{H}_{2}\left(v^{\prime \prime}\right)$ reactive collisions for high vibrational and translational energies, which are the existing conditions in the shock wave layers created by relatively large meteorites, reentry space vehicles, and hypersonic missiles. The authors find that the main product of the reaction is $\mathrm{N}_{2}+\mathrm{H}+\mathrm{H}$ with the vibrational energy in the $\mathrm{H}_{2}$ reactant having a determinant role in the dissociation process. The conversion of a considerable quantity of molecular hydrogen in atomic hydrogen is then viewed as having potential significant impact in important atmospheric reactions where atomic hydrogen is a reactant. However, the lack of experimental data for the high temperatures considered in this work hinders a direct comparison with the theoretical results.

In the second paper, Xie and Elm [2] study the formation of atmospheric clusters, which are believed to be the initial step of atmospheric aerosol particle formation. The latter are known to have an impact on global climate and to also act as seeds in cloud formation. Sulfuric acid (SA) is known to be an essential part of this process, and in this research paper, the authors investigate potential synergistic effects between different bases capable of enhancing SA-base cluster formation. Their quantum chemical studies show that there is a synergistic effect between the three studied bases present in these SA-base clusters. Hence, for SA-base clusters, it is very likely that mixed base clusters with three, or potentially more bases are involved in the cluster formation pathways. Therefore, the authors suggest that similar investigations should be extended to larger systems to allow detailed cluster kinetics modelling.

In the third piece, Zhang et al. [3] use density functional theory and conventional transition state theory to study the reaction mechanism and kinetics of the most stable ethylbenzene-OH adduct (EB-Ortho) with $\mathrm{O}_{2}$ and $\mathrm{NO}_{2}$. The authors suggest nine possible 
pathways, three for EB-Ortho $+\mathrm{O}_{2}$ and six for EB-Ortho $+\mathrm{NO}_{2}$. It was found that, at atmospheric conditions, the major product for the former reaction is ethyl-phenol while for the latter reaction one obtains nitro-ethylbenzene as the major product. The calculated rate constants show an interesting parallelism and agreement with the experimental rate constants of the toluene-OH adduct reactions with $\mathrm{O}_{2}$ and $\mathrm{NO}_{2}$. Since ethylbenzene is expected to be a precursor of secondary organic aerosols, the present theoretical study might provide a useful theoretical basis for interpreting the oxygen-containing and nitrogencontaining organics in anthropogenic secondary organic aerosol particles.

In the fourth paper, Vijayakumar et al. [4] dive into the well known and important subject of stratospheric ozone chemistry and perform a theoretical study on the kinetics of the reactions of ozone with halogen atoms in the stratosphere. Although the importance of halogens as catalysts in the destruction of ozone is well recognized, the number of theoretical studies on the kinetics of $\mathrm{O}_{3}$ with halogens is relatively low. In this paper, the authors focused in the improvement the theoretical understanding of these reactions and extend the temperature range beyond what is experimentally available, from 180 to $400 \mathrm{~K}$ for all three halogens with a primary focus on atmospherically relevant conditions. For the three reactions, the calculated rate coeffiecients were found to be in good agreement with the recommended values from NASA/JPL and IUPAC, thereby helping underpin the theoretical foundation for these important ozone-loss reactions.

In the fifth and last research paper, Bai [5] developed two empirical models of ozone concentration for considering the individual roles of isoprene or monoterpenes in a subtropical Pinus plantation in China. Predicting and understanding what affects ozone concentration is of crucial importance, since ozone is one of the important greenhouse gases influencing climate change on global scale, and a key constituent of pollutants produced through chemical and photochemical reactions in the atmosphere. The estimated ozone concentration was found to be in agreement with the field observations, with reasonable validation results. It is suggested to control human-induced high biogenic volatile organic compounds emissions, regulate plant cutting, and reduce $\mathrm{NOx}$ and $\mathrm{SO}_{2}$ emissions more strictly than ever before, so as to reduce $\mathrm{O}_{3}$ and fine particle formation.

Lastly, Tuck [6] writes a review where he presents his proposal for a challenging programme of research in theoretical chemistry involving ab initio simulation by molecular dynamics of an air volume, in order to quantitatively frame the effects of turbulence in the atmosphere. Tuck discusses that theoretical chemistry should have the ability to achieve this purpose, by showing that turbulence is an emergent property of fluid mechanics arising from symmetry breaking, driven by the Gibbs free energy of the most energetic molecules acting to minimize energy density. Turbulence affects chemistry, radiation and fluid dynamics at a fundamental, molecular level and is thus of basic concern to theoretical chemistry as it applies to the atmosphere, which consists of molecules in motion.

Funding: This research received no external funding.

Acknowledgments: The editors would like to thank the authors for their contributions, the reviewers for their constructive and valuable comments to improve the manuscripts, and the editorial office for the support in publishing this issue.

Conflicts of Interest: The author declares no conflict of interest.

\section{References}

1. Garrido, J.D.D.; Ballester, M.Y. A Theoretical Study of the N2 + H2 Reactive Collisions for High Vibrational and Translational Energies. Atmosphere 2021, 12, 1349. [CrossRef]

2. Xie, H.-B.; Elm, J. Tri-Base Synergy in Sulfuric Acid-Base Clusters. Atmosphere 2021, 12, 1260. [CrossRef]

3. Lu, T.; Huang, M.; Lin, X.; Zhang, W.; Zhao, W.; Hu, C.; Gu, X.; Zhang, W. Theoretical Studies on the Reaction Mechanism and Kinetics of Ethylbenzene-OH Adduct with $\mathrm{O}_{2}$ and $\mathrm{NO}_{2}$. Atmosphere 2021, 12, 1118. [CrossRef]

4. Vijayakumar, S.; Ranasinghe, D.S.; Wilmouth, D.M. Kinetics of the Reactions of Ozone with Halogen Atoms in the Stratosphere. Atmosphere 2021, 12, 1053. [CrossRef]

5. Bai, J. $\mathrm{O}_{3}$ Concentration and Its Relation with BVOC Emissions in a Subtropical Plantation. Atmosphere 2021, 12, 711. [CrossRef]

6. Tuck, A.F. Theoretical Chemistry and the Calculation of the Atmospheric State. Atmosphere 2021, 12, 727. [CrossRef] 